\title{
Infectious Mediastinitis
}

National Cancer Institute

\section{Source}

National Cancer Institute. Infectious Mediastinitis. NCI Thesaurus. Code C83815.

An acute or chronic infectious process affecting the mediastinum. 